\title{
Radiochemical Studies on the Separation of Cesium, Cobalt, and Europium from Aqueous Solutions Using Zirconium Selenomolybdate Sorbent
}

\author{
H. El-Said \\ Radioactive Isotopes and Generators Department, Hot Laboratories Center, Atomic Energy Authority, Cairo 13759, Egypt \\ Correspondence should be addressed to H. El-Said; hassanlsd@yahoo.com
}

Received 9 June 2012; Accepted 27 July 2012

Academic Editor: Yoshihiro Kudo

Copyright (C) 2013 H. El-Said. This is an open access article distributed under the Creative Commons Attribution License, which permits unrestricted use, distribution, and reproduction in any medium, provided the original work is properly cited.

\begin{abstract}
A procedure for removal and separation of $\mathrm{Cs}$, Eu and activation product of Co using zirconium selenomolybdate was developed. Interactions of ${ }^{134} \mathrm{Cs}(\mathrm{I}),{ }^{152,154} \mathrm{Eu}(\mathrm{III})$, and ${ }^{60} \mathrm{Co}(\mathrm{II})$ ions from $\mathrm{HNO}_{3}$ acid solutions with zirconium selenomolybdate matrix, dried at $50^{\circ} \mathrm{C}$, have been individually investigated by the batch equilibration method. The sorption behavior of the three ions showed a selectivity sequence in the following order: $\mathrm{Cs}(\mathrm{I})>\mathrm{Eu}(\mathrm{III})>\mathrm{Co}(\mathrm{II})$. The breakthrough capacities of zirconium selenomolybdate for $\mathrm{Cs}(\mathrm{I}), \mathrm{Eu}(\mathrm{III})$ and $\mathrm{Co}(\mathrm{II})$ were found to be $0.82,0.45$, and $0.18 \mathrm{mmol} / \mathrm{g}$ of the sorbent, respectively. A mixture of the three radionuclides $\left(1 \times 10^{-2} \mathrm{M}\right.$ each $)$ in $140 \mathrm{~mL}$ of $1 \times 10^{-2} \mathrm{M} \mathrm{HNO}_{3}$ solution was passed through $1 \mathrm{~g}$ zirconium selenomolybdate chromatographic column. Thereafter, quantitative elution of the retained $\mathrm{Co}(\mathrm{II})$ was achieved with $14 \mathrm{~mL}$ of $1 \times 10^{-1} \mathrm{M} \mathrm{HNO}_{3}$ acid solution leaving $\mathrm{Eu}(\mathrm{III})$ and $\mathrm{Cs}(\mathrm{I})$ strongly retained onto the column. Quantitative elution of Eu(III) was achieved by passing $22 \mathrm{~mL}$ $2.5 \times 10^{-1} \mathrm{M} \mathrm{HNO}_{3}$. About $89 \%$ of the retained $\mathrm{Cs}(\mathrm{I})$ was eluted with $32 \mathrm{~mL}$ of $2 \mathrm{M} \mathrm{NH}_{4} \mathrm{Cl}$ solution at a flow rate of $0.5 \mathrm{~mL} / \mathrm{min}$.
\end{abstract}

\section{Introduction}

Synthetic inorganic sorbents have many advantages over organic ones. These advantages include high selectivity to ions of some elements of potential benefits, rapid rate of uptake, stability towards high temperature and ionizing radiation doses, and acidic and moderately alkaline media $[1,2]$. In addition, they have the ability to be converted into unleachable glass or ceramic form. There are a wide variety of inorganic sorbents utilized successfully for treatment of large volume of nuclear waste effluents to separate and concentrate the radionuclides in small volume before burying and disposal of the treated liquid aquatic system and/or recovery of some valuable radionuclides for reuse in different applications [3-14]. In addition, inorganic ion exchangers can be used for treatment of industrial effluents to remove some toxic heavy metals which are frequently found in these effluents [15-21]. The proper choice is limited to a number of factors such as chemical composition of the medium, reactivity of the radionuclides present and in turn selectivity of the sorbent, solution concentration, $\mathrm{pH}$, and temperature.
Heteropolyacids and salts have found versatile radiochemical separation of mixture of radioisotopes from each other and of fission products, parent/daughter isobars separation onto chromatographic columns in the form of radioisotope generators and immobilization of exhausted radiowaste onto installed traps. Heteropolyacid sorbents such as 12-molybdocerate, zirconium-selenomolybdate, and 12tungstocerate have promising surface adsorption reactions with different metal ions in solution such as Cs, Ba, Co, Eu, $\mathrm{Zn}, \mathrm{Cd}, \mathrm{Pb}, \mathrm{Sn}, \mathrm{In}$, and $\mathrm{Ag}[14,22,23]$. Their chemical and radiation stability are suitable for their introduction in the field of chromatographic applications.

The three radioisotopes, ${ }^{137} \mathrm{Cs},{ }^{152,154} \mathrm{Eu}$, and ${ }^{60} \mathrm{Co}$, are important long-lived products in the nuclear waste. ${ }^{137} \mathrm{Cs}$ is a fission product, ${ }^{60} \mathrm{Co}$ is an activation product, and ${ }^{152,154} \mathrm{Eu}$ is fission and neutron activation product. The removal of these radioisotopes decrease the radiation level of the waste. In addition, the recovery of some valuable radionuclide such as ${ }^{137} \mathrm{Cs}$ for reuse in different applications by preparation of ${ }^{137} \mathrm{Cs} /{ }^{137 \mathrm{~m}} \mathrm{Ba}$ radioisotope generator which is used in 
medicine and industry in quality control process. ${ }^{152,154} \mathrm{Eu}$ and ${ }^{60} \mathrm{Co}$ are used for producing sealed sources which are used in medicine and industry.

The present work aims at (i) preparation of zirconium(IV) selenomolybdate, (ii) determination of batch distribution coefficients of ${ }^{134} \mathrm{Cs}(\mathrm{I}),{ }^{152,154} \mathrm{Eu}$ and ${ }^{60} \mathrm{Co}$ (II) from $\mathrm{HNO}_{3}$ solutions individually on zirconium(IV) selenomolybdate matrix, (iii) determination of the breakthrough capacities of zirconium(IV) selenomolybdate matrix for these ions, and (iv) separation of these radionuclides from each other by loading their mixture solution in $\mathrm{HNO}_{3}$ onto a chromatographic column of the matrix and eluting them subsequently with $\mathrm{HNO}_{3}$ solutions and/or other solutions of different concentrations.

\section{Experimental}

All chemicals were of A. R. grade. Distilled water was used for different solution preparations and washing. Radiometric identification and measurements were made by using a multichannel analyzer (MCA) of "Inspector 2000" model, Canberra Series, made in USA, coupled with a high-purity germanium coaxial detector (HPGe) of “GX2518” model.

2.1. Radiotracers of ${ }^{134} \mathrm{Cs},{ }^{152,154} \mathrm{Eu}$, and ${ }^{60} \mathrm{Co}$. Radionuclides of ${ }^{134} \mathrm{Cs}$ and ${ }^{60} \mathrm{Co}$ were produced by thermal neutron irradiation of $\mathrm{CsCl}$ and $\mathrm{CoCl}_{2}$ target materials in the watercooled ETRR-2 Research Reactor (Egypt) for $4 \mathrm{~h}$ at a thermal neutron flux of $1 \times 10^{14} \mathrm{n} \mathrm{cm}^{-2} \mathrm{~s}^{-1}$. Radionuclides of ${ }^{152,154} \mathrm{Eu}$ were produced by thermal neutron irradiation of $\mathrm{Eu}_{2} \mathrm{O}_{3}$ target materials in the water-cooled ETRR-1 Research Reactor (Egypt) for $48 \mathrm{~h}$ at a thermal neutron flux of $1 \times$ $10^{13} \mathrm{n} \mathrm{cm}^{-2} \mathrm{~s}^{-1}$.

2.2. Preparation of Zirconium Selenomolybdate. Zirconium selenomolybdate was prepared by mixing amounts of zirconium oxychloride, selenous acid, and ammonium molybdate with molar ratio 2:2:1 with constant stirring. The $\mathrm{pH}$ was adjusted to be 3 by adding ammonia solution. After standing for $24 \mathrm{~h}$, the precipitate was separated by suction and washed with water. The separated precipitate was dried at $50^{\circ} \mathrm{C}$, packed in chromatographic column and converted into the $\mathrm{H}^{+}$-form by passing $10^{-1} \mathrm{M} \mathrm{HNO}_{3}$ acid solution. The obtained exchanger was washed again with water and redried at $50^{\circ} \mathrm{C}$.

2.3. Batch Distribution Studies. The distribution coefficients for ${ }^{134} \mathrm{Cs}(\mathrm{I}),{ }^{152,154} \mathrm{Eu}$, and ${ }^{60} \mathrm{Co}(\mathrm{II})$ ions in aqueous $\mathrm{HNO}_{3}$ acid solutions on zirconium selenomolybdate matrix were individually determined by the static batch equilibration technique using the following equation:

$$
K_{d}=\frac{A_{i}-A_{f}}{A_{f}} \times \frac{V}{m}(\mathrm{~mL} / \mathrm{g}),
$$

where $A_{i}$ and $A_{f}$ are the counting rates of the aqueous phase before and after equilibration with the gel matrix, respectively, $V$ is the volume of the aqueous phase $(10 \mathrm{~mL})$, and $m$ is the weight of the gel matrix $(0.1 \mathrm{~g})$.

2.4. Capacity Studies. Chromatographic column breakthrough investigations were conducted by passing $\mathrm{HNO}_{3}$ solutions $\left(10^{-2} \mathrm{M}\right)$ of appropriate volumes $10^{-2} \mathrm{M}$ of each of ${ }^{134} \mathrm{Cs}(\mathrm{I}),{ }^{152,154} \mathrm{Eu}$, and ${ }^{60} \mathrm{Co}$ (II) individually through glass columns $(0.6 \mathrm{~cm}$ i.d.) packed with $1 \mathrm{~g}$ of zirconium selenomolybdate matrix at a flow rate of $0.5 \mathrm{~mL} / \mathrm{min}$. The breakthrough capacities (Q's) of these ions were calculated from the following equation:

$$
Q=\frac{C_{0} V_{50 \%}}{w}(\mathrm{mmol} / \mathrm{g})
$$

where $C_{0}$ is the initial metal ion concentration of the corresponding nuclide (M) in its feeding solution, $V_{50 \%}$ is the effluent volume $(\mathrm{mL})$ at $C / C_{0}=0.5$ (as indicated by measuring the counting rates of the initial solution and different effluent fractions), and $w$ is the weight of the column matrix.

2.5. Chromatographic Separation. A mixture solution of ${ }^{134} \mathrm{Cs}(\mathrm{I}),{ }^{152,154} \mathrm{Eu}$, and ${ }^{60} \mathrm{Co}(\mathrm{II})$ ions in $\mathrm{HNO}_{3}$ acid $\left(10^{-2} \mathrm{M}\right.$ and $\mathrm{pH} 2$ ) was passed through a chromatographic column $(0.6 \mathrm{~cm}$ i.d.) containing $1 \mathrm{~g}$ of zirconium selenomolybdate matrix at a flow $0.5 \mathrm{~mL} / \mathrm{min}$. The radionuclides were separated from each other by eluting the loaded column with $\mathrm{HNO}_{3}$ acid and $\mathrm{NH}_{4} \mathrm{Cl}$ solutions of different volumes and concentration.

\section{Results and Discussion}

3.1. Distribution Coefficients of Cs(I), Eu(III), and Co(II) on Zirconium Selenomolybdate Matrix. Individual interactions of ${ }^{134} \mathrm{Cs}(\mathrm{I}),{ }^{152,154} \mathrm{Eu}$ (III) and ${ }^{60} \mathrm{Co}$ (II) ions $\left(\sim 1 \times 10^{-4} \mathrm{M}\right.$ for each) in $\mathrm{HNO}_{3}$ acid solutions with zirconium selenomolybdate matrix, dried at $50^{\circ} \mathrm{C}$, were investigated by the batch equilibration method under comparable experimental conditions to make possible evaluation of the obtained $K_{d}$ values for the retention and separation of these ions. Figure 1 displays the variation of the $K_{d}$ values of ${ }^{134} \mathrm{Cs}(\mathrm{I}),{ }^{152,154} \mathrm{Eu}(\mathrm{III})$, and ${ }^{60} \mathrm{Co}(\mathrm{II})$ radionuclides individually in $\mathrm{HNO}_{3}$ acid solutions on zirconium selenomolybdate as a function of the acid concentration in the range from $1 \times 10^{-3}$ to $1 \mathrm{M} \mathrm{HNO}_{3}$. It is observed that the $K_{d}$ values ${ }^{134} \mathrm{Cs}(\mathrm{I}),{ }^{152,154} \mathrm{Eu}(\mathrm{III})$, and ${ }^{60} \mathrm{Co}$ (II) radionuclides decrease with increasing the acid concentration in the equilibrating solutions. The obtained results may be attributed to the greater competition between the respective cations in solution to exchange with $\mathrm{H}^{+}$-ions on the surface of zirconium selenomolybdate. The retention behaviour of ${ }^{134} \mathrm{Cs}(\mathrm{I})$ and ${ }^{152,154} \mathrm{Eu}(\mathrm{III})$ on zirconium selenomolybdate is characterized by plateaus (of almost $K_{d}$ values of $1160,280 \mathrm{~mL} / \mathrm{g}$, resp.) in dilute acid solutions of concentration up to $8 \times 10^{-2}$ and $3 \times 10^{-2} \mathrm{M}$, respectively. Thereafter, the corresponding $K_{d}$ values linearly decrease with increasing the acid concentration. It is also observed that 


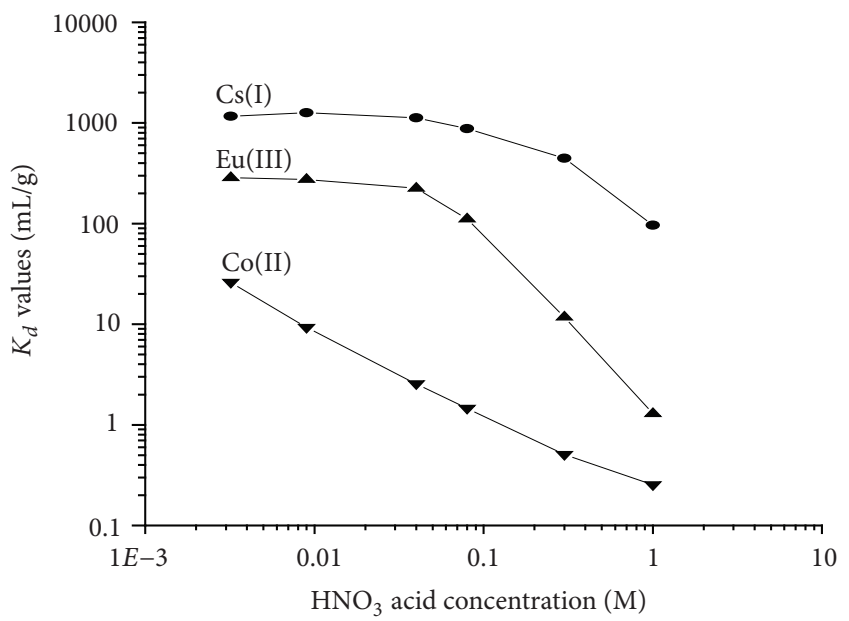

FIgURE 1: Distribution coefficients of ${ }^{134} \mathrm{Cs}(\mathrm{I}),{ }^{152,154} \mathrm{Eu}(\mathrm{III})$, and ${ }^{60} \mathrm{Co}(\mathrm{II})$ in $\mathrm{HNO}_{3}$ acid solutions on zirconium selenomolybdate matrix as a function of the acid concentration.

the $K_{d}$ values of the three nuclides increase in the following order:

$$
\mathrm{Cs}(\mathrm{I})>\mathrm{Eu}(\mathrm{III})>\mathrm{Co} \text { (II) } \text {. }
$$

This selectivity sequence may be attributed to the fact that $\mathrm{Cs}(\mathrm{I})$ ions are more able to diffuse through the sorbent and reach a higher number of the exchange sites than $\mathrm{Eu}(\mathrm{III})$ and $\mathrm{Co}(\mathrm{II})$. This may be attributed to that $\mathrm{Cs}(\mathrm{I})$ ions have larger effective ionic radii than $\mathrm{Eu}(\mathrm{III})$ and $\mathrm{Co}(\mathrm{II})$ ions and can easily be dehydrated [2]. In addition, The higher $K_{d}$ values for $\mathrm{Cs}(\mathrm{I})$ compared with $\mathrm{Eu}(\mathrm{III})$ and $\mathrm{Co}(\mathrm{II})$ on zirconium selenomolybdate may be attributed to the high selectivity of the heteropolyacids for large monovalent cations (LMC's) such as $\mathrm{Cs}(\mathrm{I}), \mathrm{Ag}(\mathrm{I})$, and $\mathrm{Tl}(\mathrm{I})$, which form insoluble heteropolyacid salts $[2,23]$. Table 1 compiles the calculated separation factors $(\alpha)$ of $\mathrm{Cs}(\mathrm{I}), \mathrm{Eu}(\mathrm{III})$ and $\mathrm{Co}(\mathrm{II})$ from each other.

3.2. Breakthrough Capacities of $\mathrm{Cs}(\mathrm{I}), \mathrm{Eu}(\mathrm{III})$, and $\mathrm{Co}(\mathrm{II})$ on Zirconium Selenomolybdate Matrix. Figure 2 illustrates the breakthrough behaviour of ${ }^{134} \mathrm{Cs}(\mathrm{I}),{ }^{152,154} \mathrm{Eu}(\mathrm{III})$, and ${ }^{60} \mathrm{Co}(\mathrm{II})$ from $1 \mathrm{~g}$ zirconium selenomolybdate column $\left(0.6 \mathrm{~cm}\right.$ i.d.) matrix fed with $140 \mathrm{~mL} 1 \times 10^{-2} \mathrm{M}{ }^{134} \mathrm{Cs}(\mathrm{I})$, ${ }^{152,154} \mathrm{Eu}(\mathrm{III})$, and ${ }^{60} \mathrm{Co}(\mathrm{II})$, in $1 \times 10^{-2} \mathrm{M} \mathrm{HNO}_{3}$ acid at a flow rate of $0.5 \mathrm{~mL} / \mathrm{min}$. Figure 2 indicates (i) an immediate breakthrough of ${ }^{60} \mathrm{Co}$ (II) and $100 \%$ breakthrough at $60 \mathrm{~mL}$ effluent volume and (ii) quantitative adsorption of ${ }^{134} \mathrm{Cs}$ and ${ }^{152,154} \mathrm{Eu}$ up to $\sim 10$ and $50 \mathrm{~mL}$ effluent volume, respectively, after which concentration in the effluent is gradually increases. Substituting the values of the effluent volume corresponding to $50 \%{ }^{134} \mathrm{Cs}(\mathrm{I}),{ }^{152,154} \mathrm{Eu}(\mathrm{III})$, and ${ }^{60} \mathrm{Co}(\mathrm{II})$ breakthrough, the initial concentration $\left(C_{0}=1 \times 10^{-2} \mathrm{M}\right)$ and amount of the bed matrix ( $m=1 \mathrm{~g})(2)$, a value of 0.82 , 0.45 and $0.18 \mathrm{mmol} / \mathrm{g}$ of zirconium selenomolybdate for ${ }^{134} \mathrm{Cs}(\mathrm{I}),{ }^{152,154} \mathrm{Eu}(\mathrm{III})$, and ${ }^{60} \mathrm{Co}(\mathrm{II})$, respectively.

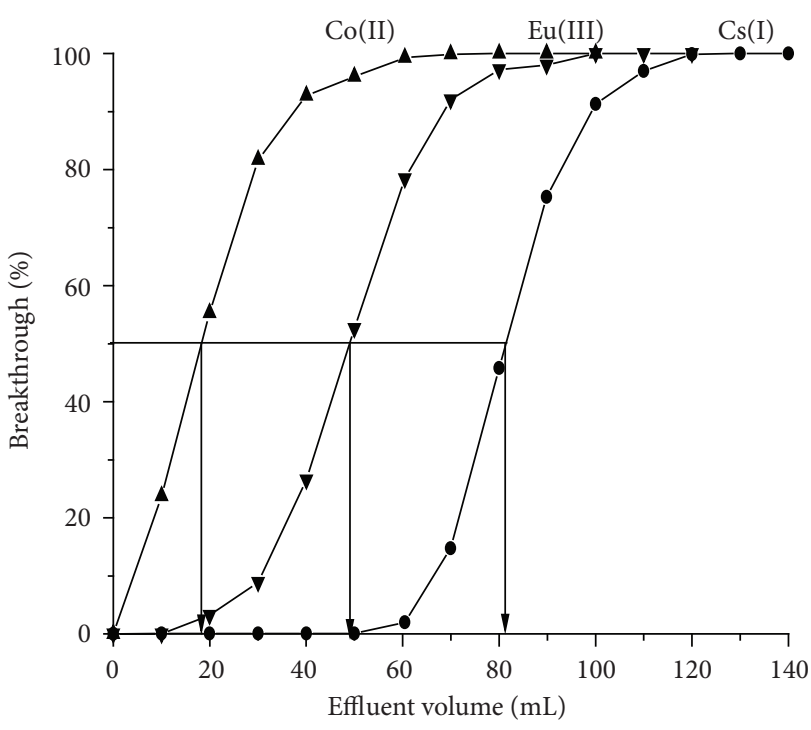

Figure 2: Breakthrough curves of $\mathrm{Cs}(\mathrm{I}), \mathrm{Eu}(\mathrm{III})$ and $\mathrm{Co}(\mathrm{II})$ from $1 \mathrm{~g}$ zirconium selenomolybdate column $(0.6 \mathrm{~cm}$ i.d. $)$ matrix using individual feeding solution of $1 \times 10^{-2} \mathrm{M}$ in $1 \times 10^{-3} \mathrm{M} \mathrm{HNO}_{3}$ acid at a flow rate $0.5 \mathrm{~mL} / \mathrm{min}$.

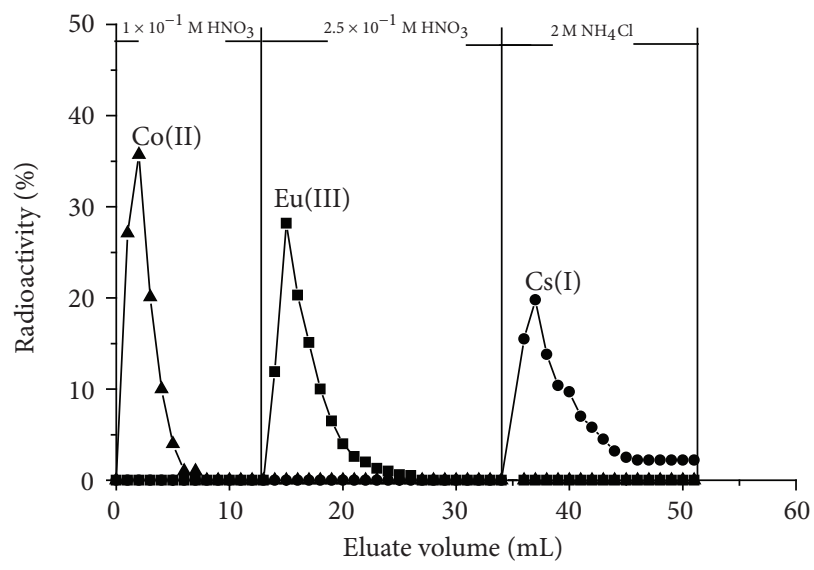

Figure 3: Elution profiles of $\mathrm{Cs}(\mathrm{I}), \mathrm{Eu}(\mathrm{III})$, and $\mathrm{Co}(\mathrm{II})$ from $1 \mathrm{~g}$ zirconium selenomolybdate column $\left(0.6 \mathrm{~cm}\right.$ i.d.) with $\mathrm{HNO}_{3}$ and $\mathrm{NH}_{4} \mathrm{Cl}$ solutions, at a flow rate $0.5 \mathrm{~mL} / \mathrm{min}$.

3.3. Separation of Cs(I), Eu(III), and Co(II) Using a Zirconium Selenomolybdate Chromatographic Column. A mixture of $\mathrm{Cs}(\mathrm{I}), \mathrm{Eu}(\mathrm{III})$, and $\mathrm{Co}(\mathrm{II})\left(1 \times 10^{-2} \mathrm{M}\right.$ each $)$ in $140 \mathrm{~mL}$ of $1 \times 10^{-2} \mathrm{M} \mathrm{HNO}_{3}$ acid solution was passed through a $1 \mathrm{~g}$ zirconium selenomolybdate column $(0.6 \mathrm{~cm}$ i.d. $)$ at a flow rate of $0.5 \mathrm{~mL} / \mathrm{min}$. Figure 3 shows the elution profiles of $\mathrm{Cs}(\mathrm{I})$, $\mathrm{Eu}(\mathrm{III})$, and zirconium selenomolybdate column $(0.6 \mathrm{~cm}$ i.d.) at a flow rate of $0.5 \mathrm{~mL} / \mathrm{min}$. It is observed that $\mathrm{Co}(\mathrm{II})$ of the lower affinity for the bed matrix immediately passed along the column bed matrix leaving $\mathrm{Eu}(\mathrm{III})$ and $\mathrm{Cs}(\mathrm{I})$ of relatively higher affinity build up onto the bed matrix. The retained Co(II) was eluted from the column bed by passing $14 \mathrm{~mL}$ $1 \times 10^{-1} \mathrm{M} \mathrm{HNO}_{3}$ acid solution at a flow rate $0.5 \mathrm{~mL} / \mathrm{min}$. Thereafter, quantitative elution of $\mathrm{Eu}(\mathrm{II})$ was achieved by 
TABLE 1: The calculated separation factors $(\alpha)$ of $\mathrm{Cs}(\mathrm{I}), \mathrm{Eu}(\mathrm{III})$ and Co(II).

\begin{tabular}{lccc}
\hline \multirow{2}{*}{$\begin{array}{l}\text { Acid } \\
\text { concentration, M }\end{array}$} & $K_{\mathrm{dCs}(\mathrm{I})} / K_{\mathrm{dEu}(\mathrm{III})}$ & $K_{\mathrm{dCs}(\mathrm{I})} / K_{\mathrm{dco}(\mathrm{II})}$ & $K_{\mathrm{dEu}(\mathrm{III})} / K_{\mathrm{dco}(\mathrm{II})}$ \\
\hline $3 \times 10^{-3}$ & 4.2 & 38.7 & 9.4 \\
$1 \times 10^{-2}$ & 4 & 118.5 & 29.5 \\
$4 \times 10^{-2}$ & 4.1 & 395.7 & 96.7 \\
$8 \times 10^{-2}$ & 8.4 & 666.7 & 80 \\
$3 \times 10^{-1}$ & 50 & 1250 & 25 \\
1 & 100 & 700 & 7 \\
\hline
\end{tabular}

passing $22 \mathrm{~mL} 2.5 \times 10^{-1} \mathrm{M} \mathrm{HNO}_{3}$ acid solution at a flow rate of $0.5 \mathrm{~m} / \mathrm{min}$. Cs(I) was strongly adsorbed onto the matrix because of the formation of insoluble heteropolyacid salts which is often the case with large monovalent cations and heteropolyacids. Consequently, it typically requires another monovalent cations of very similar bar ionic radius to exchange $\mathrm{Cs}(\mathrm{I}) . \mathrm{NH}_{4} \mathrm{Cl}$ was used for the elution of Cs. About $89 \%$ of $\mathrm{Cs}(\mathrm{I})$ was eluted with $32 \mathrm{~mL} 2 \mathrm{M} \mathrm{NH}_{4} \mathrm{Cl}$ solution at a flow rate of $0.5 \mathrm{~mL} / \mathrm{min}$. Complete recovery of $\mathrm{Cs}(\mathrm{I})$ could be achieved after decomposing the adsorbent.

As a heteropolyacid salt zirconium selenomolybdate is very selective for cesium. But comparing zirconium selenomolybdate with 12-tungstocerate we found that Cs was recovered completely with $2 \mathrm{M} \mathrm{HNO}_{3}$ acid solution but in our study about $89 \%$ of the retained $\mathrm{Cs}(\mathrm{I})$ was eluted with $2 \mathrm{M} \mathrm{NH}_{4} \mathrm{Cl}$ solution which means it is adsorbed strongly enable us in a following study to separate parent $\left({ }^{137} \mathrm{Cs}\right) /$ daughter $\left({ }^{137 m} \mathrm{Ba}\right)$ isobars onto chromatographic columns in the form of radioisotope generators.

\section{Conclusion}

Chromatographic column of zirconium selenomolybdate was used successfully for separation of cesium, europium, and cobalt from their aqueous mixture solution by elution with $\mathrm{HNO}_{3}$ and $\mathrm{NH}_{4} \mathrm{Cl}$.

\section{Acknowledgment}

The authors would like to express their appreciation for support of colleagues in Radioactive Isotopes and Generators Department, Hot Labs. Center, Egyptian Atomic Energy Authority.

\section{References}

[1] A. Mushtaq, "Inorganic ion-exchangers: their role in chromatographic radionuclide generators for the decade 1993-2002," Journal of Radioanalytical and Nuclear Chemistry, vol. 262, no. 3, pp. 797-810, 2004.

[2] M. Qureshi and K. G. Varshney, Inorganic Ion Exchangers in Chemical Analysis, CRC Press, Boca Raton, Fla, USA, 1991.

[3] V. V. Pushkarev, Y. V. Egorov, E. V. Tkachenko, and V. L. Zolotavin, "The clarification and purification of radioactive waste water by the flotation method," Soviet Atomic Energy, vol. 16, no. 1, pp. 50-52, 1964.

[4] A. S. Mollah, A. Begum, and M. M. Rahman, "Removal of radionuclides from low level radioactive liquid waste by precipitation," Journal of Radioanalytical and Nuclear Chemistry, vol. 229, no. 1-2, pp. 187-189, 1998.

[5] M. Kyrš, K. Svoboda, P. Lhoták, and J. Alexová, "Synergistic solvent extraction of $\mathrm{Eu}, \mathrm{Sr}$ and $\mathrm{Cs}$ into chlorobenzene solutions of the three conformers of tetrathiocalixarene and dicarbollide," Journal of Radioanalytical and Nuclear Chemistry, vol. 258, no. 3, pp. 497-509, 2003.

[6] P. Rajec, L. Mátel, J. Orechovská, J. Šúcha, and I. Novák, "Sorption of radionuclides on inorganic sorbents," Journal of Radioanalytical and Nuclear Chemistry, vol. 208, no. 2, pp. 477-486, 1996.

[7] B. El-Gammal and S. A. Shady, "Chromatographic separation of sodium, cobalt and europium on the particles of zirconium molybdate and zirconium silicate ion exchangers," Colloids and Surfaces A, vol. 287, no. 1-3, pp. 132-138, 2006.

[8] J. Lehto, R. Harjula, H. Leinonen et al., "Advanced separation of harmful metals from industrial waste effluents by ion exchange," Journal of Radioanalytical and Nuclear Chemistry, vol. 208, no. 2, pp. 435-443, 1996.

[9] T. Möller, A. Clearfield, and R. Harjula, "Preparation of hydrous mixed metal oxides of $\mathrm{Sb}, \mathrm{Nb}, \mathrm{Si}$, Ti and $\mathrm{W}$ with a pyrochlore structure and exchange of radioactive cesium and strontium ions into the materials," Microporous and Mesoporous Materials, vol. 54, no. 1-2, pp. 187-199, 2002.

[10] Y. Koudsi and A. Dyer, "Sorption of 60 Co on a synthetic titanosilicate analogue of the mineral penkvilksite-2O and antimonysilicate," Journal of Radioanalytical and Nuclear Chemistry, vol. 247, no. 1, pp. 209-219, 2001.

[11] S. Lahiri, K. Roy, S. Bhattacharya, S. Maji, and S. Basu, "Separation of ${ }^{134} \mathrm{Cs}$ and ${ }^{152} \mathrm{Eu}$ using inorganic ion exchangers, zirconium vanadate and ceric vanadate," Applied Radiation and Isotopes, vol. 63, no. 3, pp. 293-297, 2005.

[12] R. Koivula, R. Harjula, and J. Lehto, "Structure and ion exchange properties of tin antimonates with various $\mathrm{Sn}$ and Sb contents," Microporous and Mesoporous Materials, vol. 55, no. 3, pp. 231-238, 2002.

[13] T. J. Tranter, R. S. Herbst, T. A. Todd, A. L. Olson, and H. B. Eldredge, "Evaluation of ammonium molybdophosphatepolyacrylonitrile (AMP-PAN) as a cesium selective sorbent for the removal of ${ }^{137} \mathrm{Cs}$ from acidic nuclear waste solutions," Advances in Environmental Research, vol. 6, no. 2, pp. 107-121, 2002.

[14] H. El-Said, M. Mostafa, and M. A. El-Amir, "Study of chromatographic separation of cesium, europium, and cobalt on different types of tungstocerate column matrices," Solvent Extraction and Ion Exchange, vol. 26, no. 6, pp. 722-734, 2008.

[15] S. A. Nabi, Alimuddin, and A. Islam, "Synthesis and characterization of a new cation exchanger-zirconium(IV)iodotungstate: separation and determination of metal ion contents of synthetic mixtures, pharmaceutical preparations and standard reference material," Journal of Hazardous Materials, vol. 172, no. 1, pp. 202-207, 2009.

[16] R. Thakkar and U. Chudasama, "Synthesis and characterization of zirconium titanium phosphate and its application in separation of metal ions," Journal of Hazardous Materials, vol. 172, no. 1, pp. 129-137, 2009.

[17] F. M. Zonoz, S. J. Ahmadi, S. A. Nosrati, and M. G. Maragheh, "Preparation and characterization of zirconium (IV) molybdo 
tungsto vanado silicate as a novel inorganic ion exchanger in sorption of radionuclides," Journal of Hazardous Materials, vol. 169, no. 1-3, pp. 808-812, 2009.

[18] M. N. Akieh, M. Lahtinen, A. Väisänen, and M. Sillanpää, "Preparation and characterization of sodium iron titanate ion exchanger and its application in heavy metal removal from waste waters," Journal of Hazardous Materials, vol. 152, no. 2, pp. 640-647, 2008.

[19] Q. Zhang, B. Pan, W. Zhang et al., "Selective removal of Pb(II), $\mathrm{Cd}(\mathrm{II})$, and $\mathrm{Zn}(\mathrm{II})$ ions from waters by an inorganic exchanger $\mathrm{Zr}\left(\mathrm{HPO}_{3} \mathrm{~S}\right)_{2}$," Journal of Hazardous Materials, vol. 170, no. 2-3, pp. 824-828, 2009.

[20] E. Repo, T. A. Kurniawan, J. K. Warchol, and M. E. T. Sillanpää, "Removal of $\mathrm{Co}(\mathrm{II})$ and $\mathrm{Ni}(\mathrm{II})$ ions from contaminated water using silica gel functionalized with EDTA and/or DTPA as chelating agents," Journal of Hazardous Materials, vol. 171, no. 1-3, pp. 1071-1080, 2009.

[21] E. Repo, R. Petrus, M. Sillanpää, and J. K. Warchoł, "Equilibrium studies on the adsorption of $\mathrm{Co}(\mathrm{II})$ and $\mathrm{Ni}(\mathrm{II})$ by modified silica gels: one-component and binary systems," Chemical Engineering Journal, vol. 172, no. 1, pp. 376-385, 2011.

[22] A. P. Gupta, G. L. Verma, and S. Ikram, "Studies on a new heteropolyacid-based inorganic ion exchanger; zirconium(IV) selenomolybdate," Reactive and Functional Polymers, vol. 43, no. 1, pp. 33-41, 2000.

[23] H. El-Said, M. Mostafa, and M. A. El-Amir, "Potential use of tungstocerate matrices on the separation of ${ }^{113 \mathrm{~m}}$ In from ${ }^{110 \mathrm{~m}} \mathrm{Ag}$ relevant to the separation of the cyclotron-produced ${ }^{111}$ In from its silver target," Journal of Radioanalytical and Nuclear Chemistry, vol. 279, no. 1, pp. 263-269, 2009. 

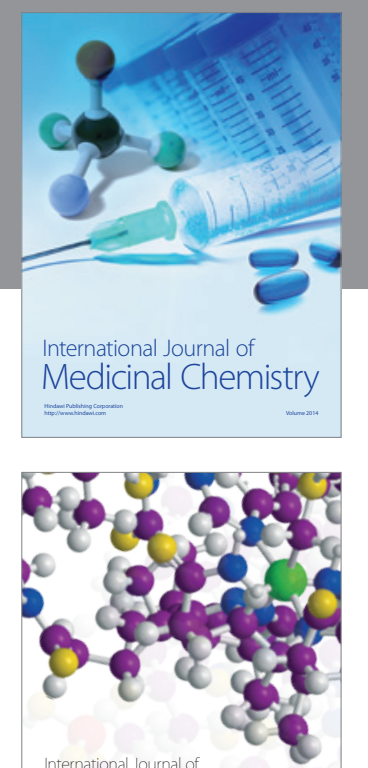

\section{Carbohydrate} Chemistry

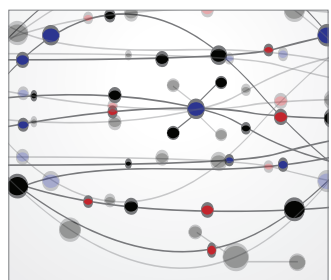

The Scientific World Journal
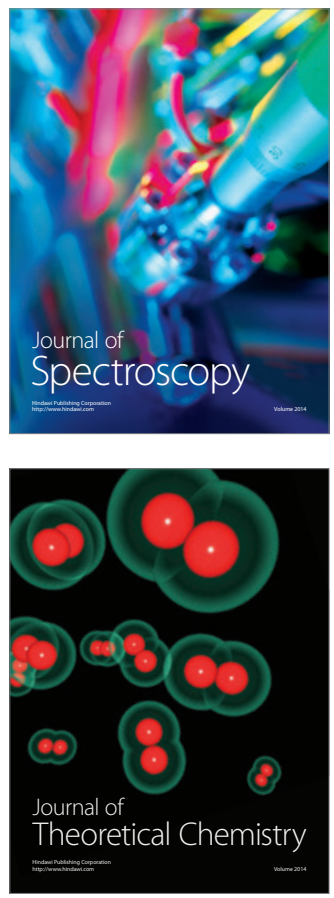
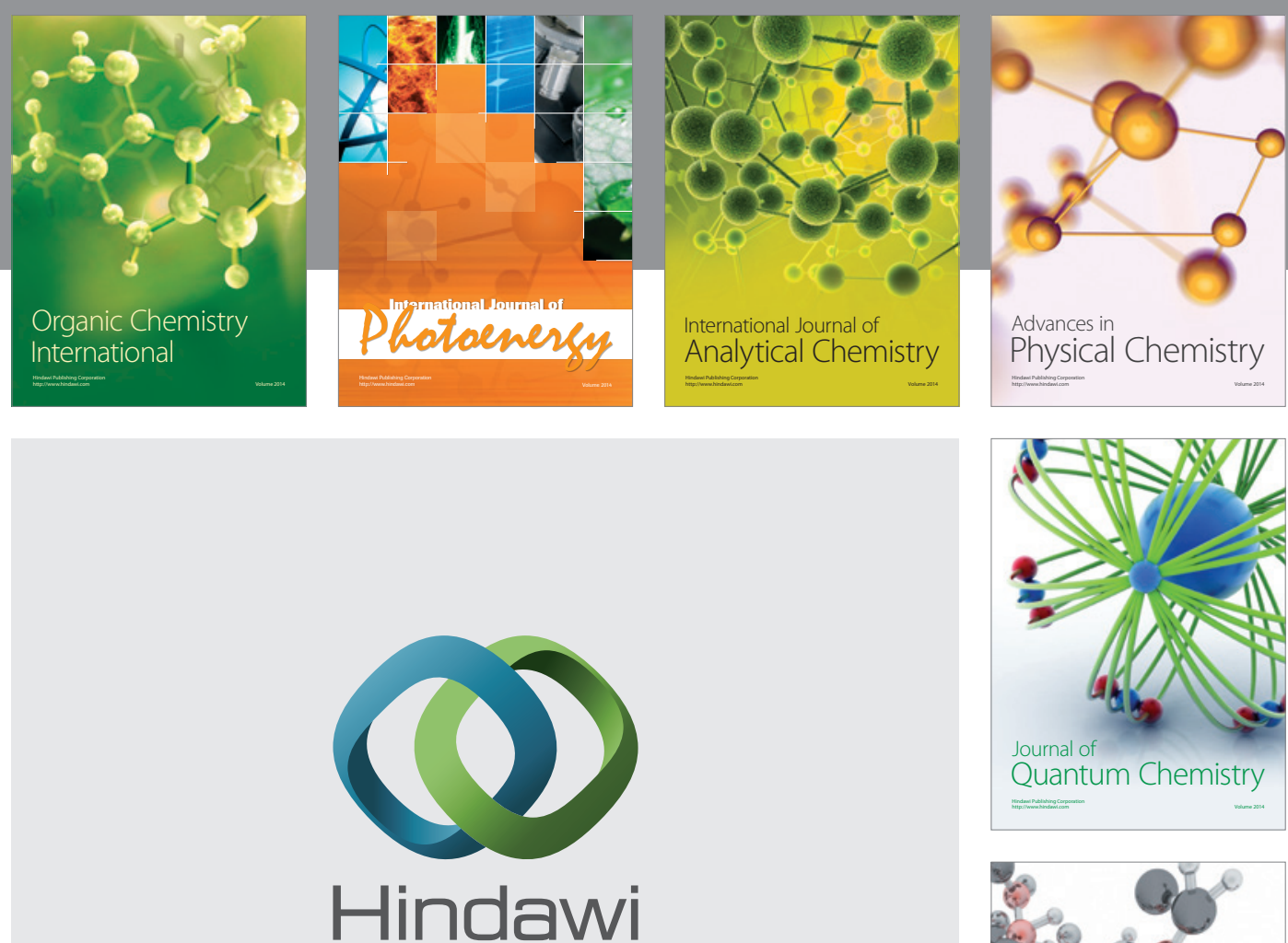

Submit your manuscripts at

http://www.hindawi.com

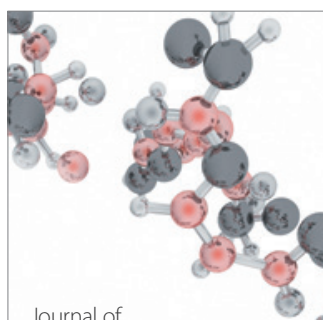

Analytical Methods

in Chemistry

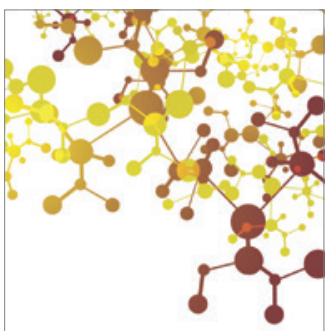

Journal of

Applied Chemistry

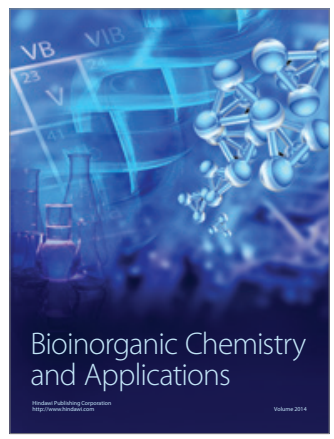

Inorganic Chemistry
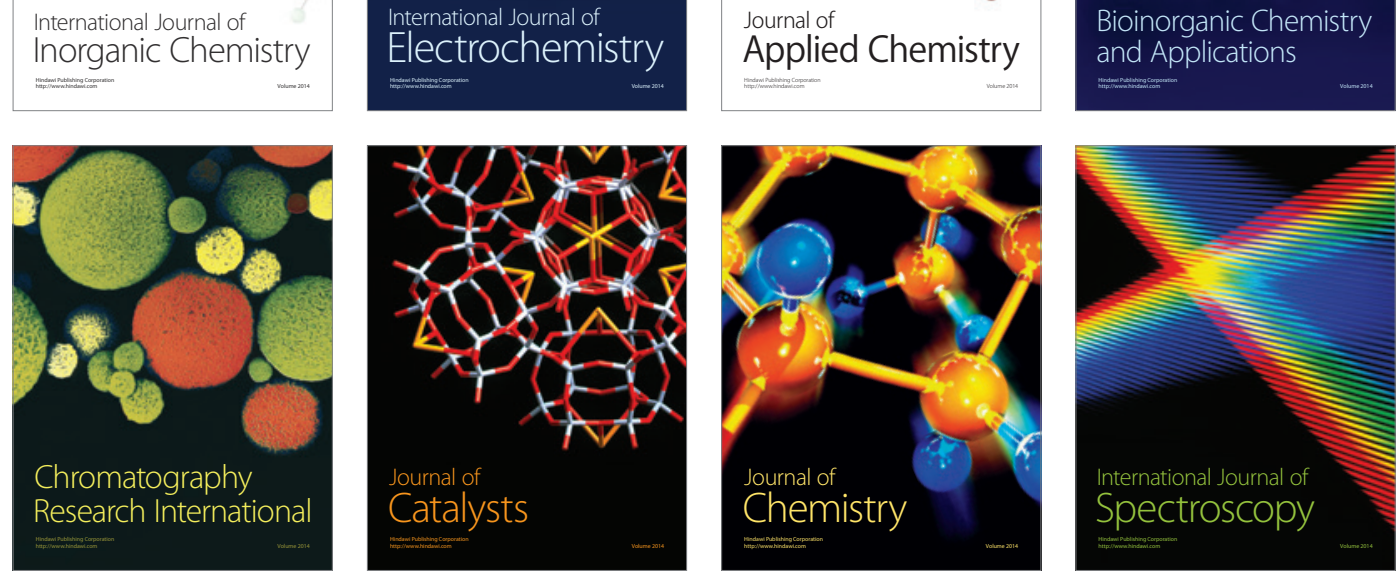